\title{
Ozone Variability over Egypt
}

\author{
Ayman Badawy ${ }^{1, *}$, Heshmat Abdel Basset ${ }^{2, *}$ and Mohamed Eid ${ }^{2}$ \\ ${ }^{1}$ Egyption Meteorological Authority, El Khalifa El Maamoun St., Kobry El Koba, Cairo, P.O.BOX \\ 11784, Egypt; \\ ${ }^{2}$ Department of Astronomy and Meteorology, Faculty of Science, Al-Azhar University, 1 Al Mokhaym \\ Al Daem, Gameat Al Azhar, Nasr City, Cairo, Egypt. \\ * Correspondence: mnbadawe4@gmail.com (A.B.); heshmatm@yahoo.com (H.A.B.)
}

\begin{abstract}
The variability of ozone over Egypt has been studied in this work. Higher values of coefficient of variation $(\mathrm{COV})$ at eight stations occur at winter while lowest values occur at summer. The $\mathrm{COV}$ is function of latitude in annual, winter and spring where it decreases gradually from the north to south of Egypt. The trend analysis of ozone over the eight stations indicates negative trends over northern stations for both annual and seasonal time series with the greatest one at winter. The horizontal distribution of ozone trend values is negative over all Egypt in winter while it positive over middle and south Egypt in the other seasons. The long-term variability of the behavior of the annual ozone shows positive trend values in ozone are the dominant features during the period 1979- 1989 at the most stations. Negative trend values in ozone are the dominant features during the period 1990- 2014 at all stations. The Mann-Kendall test confirms that there is an abrupt change towards decreasing of ozone occurs in 1981, 1984, 2012, 1999, 2000, 1998 and 2010, while a change towards increasing of ozone appears in 2006, 2014, 1993 and 1989.
\end{abstract}

Keywords: total ozone; seasonal variation; analysis trend; homogeneity; abrupt change

\section{Introduction}

Global total column ozone amounts (which are dominated by ozone in the stratosphere) declined by a few percent between roughly the 1970 s and the start of the current century (WMO, 2011), Total ozone at any location on the globe is defined as the sum of all the ozone in the atmosphere directly above that location (David. W. et al, 2014), although its small proportion in terms of the total atmospheric composition, ozone plays an important role in global weather and climate as well as surface ecology. Ozone 
prevents most harmful UV radiation from reaching the biosphere, Due to this high energy, UV-B radiation can have several harmful impacts on human beings ( DNA damage, skin cancers, corneal damage, cataracts, immune suppression, aging of the skin, and erythema), on ecosystems, and on materials ( UNEP, 1998, 2003). So we have to protect ozone layer from depletion, the study variation and trend of total column ozone is very important to detected its behavior many early studies has performed to the trend of ozone depletion, one of the ways to study the time series behavior is Abrupt change, which can be generally defined as occurring when some part of the climate system passes a threshold or tipping point resulting in a rapid change that produces a new state lasting decades or longer (Alley et al., 2003). In this case "rapid" refers to timelines of a few years to decades.

Both satellite and ground based data have documented a process of high stratospheric ozone depletion in the Antarctic environment during spring months (Farman et al., 1985; Stolarski et al., 1986). While this effect cannot be expected to apply in other places to the same extent, studies that are more recent have indicated that ozone depletion is not confined to Antarctica, but that it has global features (Atkinson et al., 1989; Bojkov et al., 1990; Stolarski et al., 1991, 1992). There is some evidence showing that the decreased ozone levels have caused increases of ultraviolet radiation at the surface (Kerr and McElroy, 1993). Analyses of total ozone have focused on trend analysis (Reinsel et al., 1994; Bojkov and Fioletov, 1995) due to the increasing concern about dramatically decreasing stratospheric ozone. However, a full description of the variability of ozone should also include means, seasonal variation and extremes. This information should be more useful in understanding ozone dynamics. Evidence of global stratospheric ozone loss has been largely based on satellite observations. "Over the northern hemisphere middle and high latitudes, data from Dobson stations have been used (Krzyscin, 1994). To measure long term trends in total ozone, an accurate instrument is required. The Brewer type spectrophotometer has proven to be one of the world's most accurate ozonemeasuring devices (WMO, 1994). It should be remembered that ground-based instruments give point measurements, while satellite data cover a certain area. The objective of this work is to study the variability and trend analysis of total column ozone over Egypt. 


\section{Data}

In Egypt there are four stations providing ground-based total ozone measurements. Table 1 illustrates the name, location, the instrument type used to measure total ozone and the period of measurements for each station. Occasionally, there are missing data (about $1 \%$ of the total data) which need to be dealt with in some fashion for calculation of the climatology. Linear interpolation is used to estimate missing values in order to make the time series complete, which enables a computation of monthly and yearly means and a time series analysis of the daily data. We also extract another four time series of TCO for the previous four stations from reanalysis ERA- Intrem total column ozone data (http://apps.ecmwf.int/datasets/data/interim-full-moda). To cover and represent the different regions of Egypt we also obtain the time series of TCO for the stations Alex $\left(29^{\circ} \mathrm{E}, 31^{\circ} \mathrm{N}\right)$, Ismail $\left(32^{\circ} \mathrm{E}, 30^{\circ} \mathrm{N}\right)$, Dahab $\left(34^{\circ} \mathrm{E}, 28^{\circ} \mathrm{N}\right)$ and Ewinat $\left(28^{\circ} \mathrm{E}, 22^{\circ} \mathrm{N}\right)$. The comparison between TCO of ground based station and its corresponding reanalysis data has been verified over Cairo and represented in Fig. 1. It is found that there is a very good agreement between observed and reanalysis data, where the correlation coefficient is 0.91 and the root mean square error is 6.1 , this good agreement allowing us to use this data in our study. Figure 2 shows the study area and the location of eight stations, four of them are the ground-based stations while the other four stations we used the reanalysis ozone data. The reanalysis daily and monthly data for total amount of ozone and other meteorological parameters are obtained from (http://apps.ecmwf.int/datasets/data/interimfull-moda). ERA-Interim reanalysis data is the latest global atmospheric reanalysis data set of the European Center Weather Forecast (ECMWF) with period from 1979 till 2014 with resolution $1^{\circ} \times 1^{\circ}$ is used for obtain total column ozone from meteorological parameters.

\section{Methodology}

Bartlett test con be used to examine the homogeneity of the data when Gaussian distribution of values is considered. The method is simply accomplished by dividing the considered time series into $\mathrm{K}$ equal subperiod $(\mathrm{k} \geq 2)$. The sample variance $S_{k}^{2}$ is 
calculated using the following relation (Mitchell et al. 1966):

$$
S_{k}^{2}=\frac{1}{n}\left(\sum x_{i}^{2}-\frac{1}{n}\left(\sum x_{i}\right)^{2}\right)
$$

Where the summations range over the $\mathrm{n}$ values of the Series, $\Sigma \mathrm{i}$ in the subperiod K. The estimated ratio between the maximum and minimum values $\left(S_{\max }^{2} / S_{\min }^{2}\right)$ is compared with the values given in table 31 of Pearson and Hartley (1958) to determine the percentage value of significance.

A coefficient of variation ( $\mathbf{C O V}$ ) for each individual station has been determined as follows:

COV $=100 * S D / \mu$

Where, $\mathrm{SD}$ is the standard deviation and $\mu$ is the temporal mean for $N$ years.

Different methods have been applied to study the trend and fluctuations of ozone over the studied area. These methods are; (a) Linear regression by using Least Square method (Panofsky and Brier ,1963), (b) Gaussian low-pass filter (Mitchell et al 1966), (c) Binomial low-pass filter (Mitchell et al. ,1966 and Tyson et al.,1975). Also the nonparametric Mann-Kendall (M-K) rank correlation test (Sneyers, 1990; Schonwiese and Rapp, 1997; Hasanean, 2004) has been used to detect any possible trend in ozone series, and to test whether or not such trends are statistically significant. To visualize the decadal and inter-decadal fluctuations or "persistence" in the behavior of the KSA ozone, cumulative seasonal means method is used (Pavia and Graef 2002). The advantage of this is to reveal time varying structures in time series. The cumulative seasonal means time series can be defined as;

$y_{j}=\frac{1}{j} \sum_{i=1}^{j} x_{i}, \quad j=1,2, \ldots \ldots \ldots \ldots . . . . ., N$.

Where, $x_{i}$ is the total amount of ozone and $N$ is the number of years of data used.

\section{Abrupt change procedur:}

"To statistically identify the abrupt climatic changes in the annual mean TCO time series, the nonparametric Mann-Kendall (MK) rank statistic is employed (Sneyers 1975, 1990). This is a suitable method for testing any abrupt change in mean values (Goossens and Berger 1986; XiaoHui and XiangDe 2007). The MK method can be considered in 
detecting the beginning of any change in a time series (Goossens and Berger 1986). The intersection between the two resulting trend lines in the region \pm 1.96 of the standardized statistic, at the $5 \%$ significant level, is considered to be an evidence of an abrupt change in the time series. Estimation of MK rank statistic is done by considering only the relative values of all the terms in the time series $X_{i}$ under analysis and replacing the $X_{i}$ values with their ranks $Y_{i}$, arranged in increasing order. For each element $Y_{i}$, the number $n_{i}$ of elements $Y_{j}$ preceding it, i.e. $\left.(i\rangle j\right)$ is calculated such that $\left.Y_{i}\right\rangle Y_{j}$. The statistical test $T_{i}$ is then given by the following formula:

$T_{i}=n_{1}+n_{2}+\ldots \ldots+n_{i}$

This sum is standardized to a normal distribution by

$u\left(T_{i}\right)=\left[T_{i}-E\left(T_{i}\right)\right] / \sqrt{\operatorname{var}\left(T_{i}\right)}$

Where the mean $E\left(T_{i}\right)$ and variance $\operatorname{var}\left(T_{i}\right)$ are defined as

$E\left(T_{i}\right)=\frac{i(i-1)}{4}, \quad \operatorname{var}\left(T_{i}\right)=\frac{i(i-1)(2 i+5)}{72}$

A significant trend at the threshold $\alpha_{1}$ (e.g., 0.05) is observed when $u\left(T_{i}\right) \succ \alpha_{1}$. The probability $\alpha_{1}$ threshold is determined by the means of the standard normal distribution table, such that

$\left.\alpha_{1}=p(|u|\rangle\left|u_{i}\right|\right)$.

If the values of $u\left(T_{i}\right)$ are significant, then they can be considered whether the trend is increasing or decreasing, by looking at how $u\left(T_{i}\right)$ itself increases or decreases. However, when a series shows a significant trend, it is necessary to locate the start of the abrupt change by means of a sequential analysis. In this case, the analysis is performed with the same time series but with reversed sequence. To identify an abrupt change in the time series, this analysis is performed with the same SAT time series but with the reverse sequence, i.e., number $n_{i}^{\prime}$ of $Y_{j}$ terms for each $Y_{i}$ term, such that $\left.Y_{i}\right\rangle Y_{j}$ with $i\langle j$ will be

$n_{i}^{\prime}=Y_{i}-1-n_{i}$

So that, $i^{\prime}=(N+1)-i$

Where $\mathrm{N}$ is the total number of elements in the series. Therefore, the values of $u^{\prime}\left(T_{i}^{\prime}\right)$ for the reversed series can be calculated; this is similar to $u\left(T_{i}\right)$ as in Equation 7 . In the 
absence of any trend in the series, the graphical representation of $u$ and $u^{\prime}$ in terms of $i$ generally gives curves, which overlap several times.

\section{Mann- Whitney test for step trend}

Given the data vector $X=\left(x_{1}, x_{2}, \ldots \ldots . ., x_{n}\right)$, partition $X$ so that $Y=\left(x_{1}, x_{2}, \ldots \ldots \ldots, x_{n 1}\right)$ and $Z=\left(x_{n 1+1}, x_{n 1+2}, \ldots \ldots \ldots \ldots . ., x_{n 1+n 2}\right)$. The Manne Whitney test statistic is given as:

$Z_{c}=\left[\sum_{t=1}^{n 1} r\left(x_{t}\right)-n_{1}\left(n_{1}+n_{2}+1\right) / 2\right] /\left[n_{1} n_{2}\left(n_{1}+n_{2}+1\right) / 12\right]^{1 / 2}$

in which $r\left(x_{t}\right)$ is the rank of the observations. The null hypothesis $\mathrm{H}_{0}$ is accepted if

$-Z_{1-\alpha / 2} \leq Z_{c} \leq Z_{1-\alpha / 2}$, where $\pm Z_{1-\alpha / 2}$ are the $1-\alpha / 2$ quantiles of the standard normal distribution corresponding to the given significance level $\alpha$ for the test.

\section{Results}

\subsection{Homogenity of the data}

Study of the data homogeneity is important in climatology. Homogeneity is established differently in different climatic elements. The values of climatic elements could be the method of estimating daily and monthly averages. Artificial lakes and reservoirs and other man-made changes of local environment produce sources of inhomogeneity in historical record of climatic data.

Homogeneity of the total column ozone (TCO) of the annual and seasonal time series over Egypt stations has been detected by means of Bartlet test (described in section 3). Table 2 shows Bartlet test (short-cut) result for annual and seasonal ozone of land based stations and reanalysis data respectively. The mean annual and seasonal of TCO seems to be homogeneous for all stations regarding the ratio $\left(S_{\max }^{2} / S_{\min }^{2}\right)$ Bartlet test with 95\% significance as shown in (Mitchell et al., 1966).

\subsection{Coefficient of variation (COV)}

The variability in total column ozone at a single location is strongly influenced by the movement of air from one region to another.Thus, total column ozone averages over the entire globe, or over large regions, often show less variability than total column ozone at a specific location (Bodeker et al., 2001). 
The COV of annual, winter, spring, summer and autumn of TCO of the reanalysis (8 stations) and measured (4 stations) data is displayed in Table 3. The higher values of $\mathrm{COV}$ at all stations occur at winter while the lowest values of COV occur at autumn. The $\mathrm{COV}$ of spring at all stations are greater than those in summer and annual values. The $\mathrm{COV}$ in annual and winter decreases gradually from the northen station to the southern station. So it can be said that the COV is a function of latitude in winter and annual values. The maximum value of COV in spring and autumn for the eight stations occurs at Matrouh, it reaches 3.58 and 1.98 respectively. Also as in winter, the values of COV in spring decrease gradually from the northern station to the southern station. In summer season the behaviour of COV at our stations is different from that in winter, spring and autumn seasons, these results are more obvious in Figure 3. Figure 3 illustrates the horizontal distribution of COV for the annual and seasonal values of TCO. It is clear that the values of COV of winter, spring and annual decreases gradually from north to south of Egypt. The patterns of COV for summer and autumn are different from winter and spring, where we found that the summer values of COV decreases from west to east, it may be affected by the west ward oscillation of the Indian monsoon low. The lowest values of COV of autumn appears at the middle of south Egypt and also over the Red Sea, it may be associated with the northward oscillation of the inverted V-shep trough of Sudan low. The high variability over north Egypt in winter and spring is associated with the traveling main and secondary Mediterranean cyclones.

\subsection{Trend analysis}

The annual ozone time series for the eight stations under study have been investigated to determine their trends. The studies of trends have been performed by means of both a simple and sophisticated tools. These methods are: 1) Least square method of first order (linear regression), 2) Moving filters by using Gaussian low- pass filter and binomial low- pass filter and 3) Mann-Kendall rank statistical test. Discussion of the important aspects of the long-term variations and trends are given below for annual ozone time series.

\subsubsection{Trend by least square method}

Table 4 illustrates the values of trend by least square method for the annual and 
seasonal ozone of Egypt stations. It showed that there is a positive trend of annual and seasonal ozone at four ground-based stations. It is clear that the only negative trend occurs only in winter over Cairo (-0.15 DU/year), also the minimum annual trend value occurs at Cairo (0.03DU/year). With respect to the reanalysis TCO time series of the eight station, it is found that the maximum annual and seasonal trends occurs at Hurgada and Matrouh, it may be due to the location of these two costal stations ( Beig et al. 2007).

The trend of the reanalysis TCO time series of the eight stations is positive for the autumn season. Also, the trend of the southern three stations (Hurgada, Aswan and Ewinat) is positive for the annual and seasonal TCO time series.

\subsubsection{Fluctuation of annual Ozone}

Trends of annual ozone of the concerned stations by means of Gaussian and binomial low- pass filter (dotted curve, thin curve) has been investigated for ground based (observed) and reanalysis data (Figures 4 and 5 ).

Figure 4 illustrate the results obtained from the two methods for the observed values of TCO. Careful examination of the obtained results shows that during the period 2004 to 2013 an obvious increase of TCO occurred in Matrouh and Aswan, the increase in mean annual TCO reached to 4 DU. A pronounced decrease of TCO at Matrouh appears from 1998 to 2002, after that TCO have its average value until 2005. From 2006 to 2013 an obvious increase of TCO occurs at Matrouh, the maximum increase (4 DU) appears at the years 2009 and 2010. For Cairo station a decrease of TCO has been found from 1969 to 1977 with a maximum reached to 4 DU during 1970 to 1973 , followed by an obvious increase of TCO from 1978 to 1984. During the period from 1985 to 2014, the values of TCO fluctuate around the mean. For Hurgada a decrease of TCO is found from the beginning until 2005, this period followed by a persistence of TCO around the mean until 2009. During the last period TCO fluctuate around its mean with considered amplitude. The behavior of TCO time series in Aswan can be divides into two obvious periods, the first one is from 1990 to 2000 is dominated by a decrease of TCO. The second period (2004- 2012) is characterized by a pronounced increase of TCO.

Figure 5 illustrate the results obtained from the two methods (Gaussian and binomial low- pass filter) for the reanalysis values of TCO at eight stations. Generally, the time series of the 8 stations have nearly the same behavior, where we found that the 
behavior of each time series can be divided into five periods, the first one is from 1979 to 1983 and characterized by increase of TCO with maximum at 1980, this period followed by a respectively long period of decreasing of TCO which extended from 1982 to 1995 with maximum decrease at 1994. The third period (1995-2002) is dominated by increase of TCO with maximum at 1997. An obvious decrease of TCO occurs during the fourth period (2002- 2008) with maximum decrease at 2004. The last period (2008-2014) is characterized by increase of TCO except for Hurgada station. Although there is a considerable difference between the record length of the time series of the observed and reanalysis data, there is a high consistence between the results. As examples, the period from 2001 to 2005 represent a period of decrease of TCO in Hurgada in observed and reanalysis data, while the period 2007 to 2014 represent a period of increase of TCO. Also, there is a high consistence between the periods of increase and decrease in observed and reanalysis data of Cairo especially for the increase period 1979- 1983. Two periods of high consistence between observed and reanalysis data appears at Aswan, the first is from 2006 to 2012 while the second is from 1991 to 2000.

\subsubsection{Mann-Kendall rank statistical test}

The values of $\mathrm{M}-\mathrm{K}$ trend test ( $\mathrm{u}$ ) were valued according to Sneyers (1990). Table 5 shows the $\mathrm{M}-\mathrm{K}$ statistics for the annual, winter, spring, summer and autumn measured and reanalysis time series of the considered stations. With respective to the measured four time series, positive trends are observed over the four stations for the annual and seasonal time series except for the winter time series of Cairo. Table 5 also illustrates that both of negative and positive trend values of winter season is less than those in the other seasons. The behavior of positive and negative trends of the annual and seasonal measured and reanalysis time series of our stations (table 5) is very consistent with the corresponding values from the least square method (table 4). With respective to the reanalysis eight time series, negative trend values are dominated for the annual and winter time series of the 8 stations. For spring and summer seasons, the trend values of the northern stations (Matrouh, Alex, Ismail, and Cairo) is negative while for the middle and southern stations (Dahab, Hurgada, Aswan and Ewinat) is positive, the autumn trend is positive for all station except for Matrouh. Figures 6 illustrate the horizontal distribution of the M-K trend values of the seasonal and annual reanalysis TCO over Egypt for the period 1979- 
2014. It shows that in winter the negative trend values appears north of latitude $22^{\circ} \mathrm{N}$ and in spring north of latitude $28^{\circ} \mathrm{N}$, while in summer and autumn it appears north of $30^{\circ} \mathrm{N}$.

\subsection{Cumulative annual means}

To visualize the decadal and inter-decadal fluctuations or "persistence" in the behavior of the Egypt ozone, cumulative annual means method is used (Pavia and Graef 2002). The advantage of this is its ability to reveal time varying structures in time series. In this section, the long- term variability of the behavior of the annual ozone is analyzed with regard to the time variations of annual ozone. Cumulative annual means will be used to visualize the decadal and inter-decadal fluctuations in the behavior of the annual ozone, because they advantageously reveal time varying structures in time-series, which are not readily recognizable in raw data. Moreover, the cumulative means have a smoothing effect, similar to low-pass filters (Lozowski et al., 1989). Persistent phases of alternating increase or decrease of the ozone, which vary in length, are recognizable in the time series of the annual ozone.

Figure 7 illustrate the cumulative annual mean (CAM) time series and the averaged CAM of the measured annual values of ozone of the stations Cairo, Matrouh, Hurgada and Aswan. Results from Cairo station show that CAM time series can be divided into three periods. The first period (1968-1971) illustrates a positive trend, the second period shows a negative trend, while the last period (1981- 2014) shows a fluctuation of the trend around the CAM average. The cumulative annual means for Matrouh and Hurgda have the same behavior throughout their observational period. They show a negative trend in TCO during the first period (1998-2005) followed by a continuous positive trend until 2014. The maximum average CAM for these stations occurs in Matrouh (297.2 DU). The cumulative annual mean for Aswan throughout its observational period shows a negative ozone trend during the first period (1984-1989) followed by a positive trend until 1994. A negative trend is detected at Aswan for the period 1994- 2004 followed by a positive trend until 2014. The average CAM of this station is about $271 \mathrm{DU}$.

Figure 8 illustrate the cumulative annual mean (CAM) time series and the averaged CAM of the reanalysis annual values of ozone of the eight stations. It is clear that 
positive trend values in ozone are the dominant features during the period from 1979 to 1988 at the northern stations (Matrouh, Alex, Ismail, and Cairo), while from 1979 to 1984 at the middle and southern stations (Dahab, Hurgada, Aswan and Ewinat). Negative trend values in ozone are the dominant features during the period 1990- 2014 at the eight stations.

\subsection{Abrupt change analysis}

The concept of abrupt change is by now well established. For example Rogers (1985) described the marked changes in sea level pressure patterns of the North Atlantic during the 1920s. Flohn (1986) expanded the concept of abrupt climate change to include both singular events and catastrophes such as the extreme El Nino of 1982-1983. Trenberth (1990) and Miller et al. (1994), among others, documented a rather abrupt shift of sea surface temperature and atmospheric circulation features in the Northern Hemisphere in the mid-1970s. The concept has been extensively used as the foundation of many different methods to detect sudden irregular changes or discontinuities in SAT (Bengtsson et al. 2004; Bromwich and Fogt 2004; Trenberth and Shea 2005). Figures 9, 10 and Table 6 show the results of the Mann-Kendall rank statistic for the annual mean TOC using both the forward and backward sequential statistic methods. They reveal that abrupt climatic changes have taken place. However, the abrupt changes occur in the time series of the reanalysis data of the eight stations (Figure 10), while it occurs only in Cairo and Aswan of the measured data. Decreasing trends in TOC are evident for six stations in 1981 and 1984 (Matrouh, Alexendria, Ismail, Cairo, Dahab and Hurgada). For Aswan station, the same decreasing trends are detected around the years 1989, 1998 and 2010 (Fig. 10 and Table 6), while increasing trends appears around the years 1987, 1993 and 2008. For Ewinat station, the abrupt change toward decreasing occurs twice, in 1998 and 2009 (Fig.10 and Table 6), while increasing trends in TOC are evident in 1987, 1993 and 2008. In the time series of measured TOC of Aswan the abrupt change toward decreasing occurs in 2010, while increasing trends occurs around the period 1998 to 2004. The results of Ewinat illustrate that abrupt change toward decreasing occurs around 1998 and 2009, while increasing trends appears in 1989, 1993 and 1989. Abrupt change toward increasing of TOC occurs around the year 2006 appears at six stations (Matrouh, Alexendria, Ismail, Cairo, Dahab and Hurgada), and around 2014 at three stations 
(Ismail, Dahab, Hurgada). A trend toward decreasing around 2012 occurs in Ismail, Cairo, and Dahab. From the above results one can conclude that a change towards decreasing TOC is obtained in 1981, 1984, 2012, 1999, 2000, 1998 and 2010 and a change towards increasing TOC is obtained in 2006, 2014, 1993 and 1989 (Table 6).

The results of the Manne Whitney test for abrupt change of the time series of TOC for the four ground based stations are illustrated in Figure 11. Figure 11a shows the departure curves of the ozone in Matrouh, departure is the deference of climate variables for 17 years. The test detected abrupt change in the ozone time series of Matrouh around 2006 at the 0.01 significance level. Also there are two obvious periods in the study area for the past 17 years, the first one is the decrease period of 1989-2005, in which the negative departures account for more than $47 \%$, and the abnormal decrease years are 1998, 1999, 2002 and 2004 respectively. The second one is the increase period of 20072014, in which the mean ozone is 2.48 DU higher than the average of the whole period. In the increase period, the positive departures account for more than $52 \%$, in which the highest ozone for 17 year and the ozone in 2009 is 6.76 DU higher than that of the whole period. The Manne Whitney test detected two abrupt changes in the ozone time series of Cairo the first one is around 1979 at the 0.05 significance level while the second one is around 1993 at the 0.08 significance level, Figure $11 \mathrm{~b}$ shows the departure curves of the ozone in Cairo station. It is shown that the departure curve fluctuates significantly, with the characteristics of two decreasing and one increasing abrupt changes since the 1968s. The period of more ozone, 1980-1992, in which the mean ozone is 2.9 DU more than that of the whole period. The first period of less ozone from 1968 to 1977, in which the mean ozone is 4.49 DU less than that of the whole period. The second period of less ozone is from 1994 to 2014, in which the mean ozone is 0.29 DU less than that of the whole period.

The Manne Whitney test detected abrupt change in the ozone time series of Hurgada around 2009 at the 0.05 significance level, Figure 11c shows the departure curves of the ozone in Hurgada. Departure is the deference of climate variables for 14 years. It is shown in Figure 11c there are two obvious periods in the study area for the past 14 years. The first one is the lower period from 2001 to 2008, in which the ozone is 1.38 DU lower than that of the whole period. The second one is the higher period from 
2010 to 2014, in which the ozone is 1.83 DU higher than that of the whole period. The Manne Whitney test detected two abrupt changes in the ozone time series of Aswan the first one is around 2000 at the 0.004 significance level while the second one is around 2012 at the 0.176 significance level, Figure $11 \mathrm{~d}$ shows the departure curves of the ozone in Aswan station. It is shown that the departure curve fluctuates significantly, with the characteristics of two decreasing and one increasing abrupt changes since the 1984s. The period of more ozone, 2001-2011, in which the mean ozone is 3.5 DU more than that of the whole period. The first period of less ozone from 1984 to 1999, in which the mean ozone is 2.36 DU less than that of the whole period. The second period of less ozone is from 2013 to 2014 , in which the mean ozone is 2.48 DU less than that of the whole period.

\section{Summary and conclusions}

The variability of ozone over Egypt has been studied in this work. The studying of COV for annual, winter, spring, summer and autumn ozone indicate that higher values of COV at eight stations occur at winter while lowest values occur at summer. The COV is function of latitude in annual, winter and spring where it decreases gradually from the north to south of Egypt. The studying of the horizontal distribution of COV for the annual and seasonal values of TCO indicate that the patterns of COV for summer and autumn are different from winter and spring, where we found that the summer values of COV decreases from west to east, it may be affected by the west ward oscillation of the Indian monsoon low. The lowest values of COV of autumn appears at the middle of south Egypt and also over the Red Sea, it may be associated with the northward oscillation of the inverted V-shep trough of Sudan low. The high variability over north Egypt in winter and spring is associated with the traveling main and secondary Mediterranean cyclones. The trend analysis by least square method and Mann-kendall test for the seasonal and annual values of ozone over our stations were made. The trend analysis indicates negative trends over northern stations for both annual and seasonal time series with the greatest one at winter. The horizontal distribution of ozone trend values is negative over all Egypt in winter while it positive over middle and south Egypt in the other seasons. The long-term variability of the behavior of the annual ozone shows positive trend values in ozone are the dominant features during the period 1979- 1989 at the most stations. Negative trend 
values in ozone are the dominant features during the period 1990- 2014 at all stations. The Mann-Kendall test confirms that there is an abrupt change towards decreasing of ozone occurs in 1981, 1984, 2012, 1999, 2000, 1998 and 2010, while a change towards increasing of ozone appears in 2006, 2014, 1993 and 1989.

The study of the Manne Whitney test for abrupt change of the time series of TOC for the four ground based stations confirms that there is abrupt change in the ozone time series of Matrouh around 2006 at the 0.01 significance level. And there are two obvious periods; the first one is the decrease period of 1989-2005 in which the abnormal decrease years are 1998, 1999, 2002 and 2004 respectively. The second one is the increase period of 2007-2014, in which the mean ozone is 2.48 DU higher than the average of the whole period. The Manne Whitney test detected two abrupt changes in the ozone time series of Cairo the first one is around 1979 at the 0.05 significance level while the second one is around 1993 at the 0.08 significance level. The period of more ozone, 1980-1992, in which the mean ozone is 2.9 DU more than that of the whole period. The first period of less ozone from 1968 to 1977 , in which the mean ozone is 4.49 DU less than that of the whole period.

\section{References}

1- Alley, R.B., et al., 2003: Abrupt climate change. Science, 299(5615), 2005-2010.

2- Atkinson, R.J., Matthew, W.A., Newman, P.A. and Plumb, R.A. 1989: Evidence of the midlatitude impact of Antarctic ozone depletion, Nature, 340, 290.

3- Beig, Gufran, Singh, Vikas. 2007 Trends in tropical tropospheric column ozone from satellite data and MOZART model, GEOPHYSICAL RESEARCH LETTERS, , Volume 34, Issue 17 : DOI: 10.1029/2007GL030460.

4- Bodeker, G.E., J.C. Scott, K. Kreher and R.L. McKenzie, 2001. Global ozone trends in potential vorticity coordinates using TOMS and GOME intercompared against the Dobson network. Journal of Geophysical Research, 106(D19):2302923042.

5- Bojkov, R., Bishop, L., Hill, W.J., Reinsel, G.C. and Tiao, G.C. 1990: A statistical trend analysis of revised Dobson total ozone data over the northern hemisphere. J. Geophys. Res., 95, 9785-9807. 
6- Bojkov, R.D. and V.F. Fioletov, 1995: Estimating the global ozone charateristics during the last 30 years. J. Geophys. Res., 100, 16537-16551.

7- Bromwich, D. H., and R. L. Fogt, 2004: Strong trends in the skill of the ERA-40 and NCEP/NCAR Reanalyses in the high and middle latitudes of the Southern Hemisphere, 1958-2001. J. Climate, 17, 4603-4619.

8- C.D.Schonwiese and J.Rapp. Kluwer 1990: Climate trend atlas of Europe based on observations 1891-1990, RmetS,Vol 18, Issue 5 , 580-581

9- David W. Fahey and Michaela I. Hegglin Coordinating Lead Authors Twenty Questions and Answers About the Ozone Layer: 2014 Update

10- De la Casinière A., 2003. Le rayonnement solaire dans l'environnement terrestre. Éditions Publibook, Paris, p 264.

11-E. P. Lozowski, R. B. Charlton, C. D. Nguyen, J. D. Wilson. 1989 . The Use of Cumulative Monthly Mean Temperature Anomalies in the Analysis of Local Interannual Climate Variability Journal of Climate 2(9):1059-1068.

12-Farman J. C., B. G. Gardiner,and J. D. Shanklin, 1985. Large losses of total ozone in Antarctica reveal seasonal C10x/NOx interaction. Nature 315, 207-210.

13- Fioletov V. E. and T. G. Shepherd, 2005. Summertime total ozone variations over middle and polar latitudes. Geophys Res. Lett. 32, L04807, doi:10.1029/2004GL022080.

14-Fioletov V. E., G. E. Bodeker, A. J. Miller, R. D. McPeters and R. Stolarski, 2002. Global and zonal total ozone variations estimated from ground-based and satellitemeasurements:1964-2000.J.Geophys.Res.107, .

15- Flohn. H., 1986a. Singular events and catastrophes now and in climatic history, Naturwissenschaften, 73: 136-149

16-Global ozone trends in potential vorticity coordinates using TOMS and GOME intercompared against the Dobson network. Journal of Geophysical Research, 106(D19):23029-23042.GOOSSENS, C.; BERGER, A. Annual and seasonal climatic variations over the northern hemisphere and Europe during the last century. Annales Geophysicae, Berlin, v. 4, n. B4, p. 385-400, 1986. 
17-H.M.Hasanean 2004:Variability of the North Atlantic subtropical high and associations with tropical sea-surface temperature, RmetS.Volume 24, Issue $8,945-957$

18-Jeffery C Rogers , 1985, Atmospheric Circulation Changes Associated with the Warming over the Northern North Atlantic in the 1920s, Journal of Applied Meteorology 24(12):1303-1310.

19- Kevin E. Trenberth and Dennis J. Shea,2005, Relationships between precipitation and surface temperature, GEOPHYSICAL RESEARCH LETTERS, VOL. 32, L14703

20-Krzyscin, J.W. 1994: 'Changes in ozone trends over the northern hemisphere middle latitudes during the period 1970-1990', Theor. . Appl. Climatol. 49, 17.

21-LENNART BENGTSSON, VLADIMIRA. SEMENOV, OLAM. JOHANNESSEN, 2004, The Early Twentieth-Century Warming in the Arctic-A Possible Mechanism, Journal of Climate, 17, 4045-4057.

22-Miller, J.R., G.L. Russell, and G. Caliri, 1994: Continental-scale river flow in climate models.J.Climate,7,914-928.

23- Mitchell JM Jr, Dzerdzeevskii B, Flohn H, Hofmeyr WL, Lamb HH, Rao KN, Wallén CC (1966) Climatic Change. WMO Technica 1 Note No 79, World Meteorological Organization, Geneva, p 79.

24-Molina M. J. and F. S. Rowland, 1974. Stratospheric sink for chlorofluoromethanes: chlorine atom-catalyzed destruction of ozone. Nature 249,810-812.

25-Newchurch M. J., E.-S. Yang, D. M. Cunnold, G. C. Reinsel, J. M. Zawodny and J. M. Russell III, 2003. Evidence for slowdown in stratospheric ozone loss: First stage of ozone recovery. J. Geophys. Res. 108, doi:10.1029/2003JD003471.

26-Panofsky, H. A., and G. W. Brier, 1963:Some Applications of Statistics to meteorology . Penn State University,224 pp.

27-Pavia EG, Graef F. 2002.: The recent rainfall climatology of the Mediterranean Californias. Journal of Climate 15: 2697-2701.

28-Reinsel, G.C., Tiao, G.C., Wuebbles, D.J., Kerr, J.B. Miller, A. J., Nagatani, $\quad$ R. M., Bishop, L. and Ying, L. H. 1994: Seasonal trend analysis of published 
groundbased and TOMS total ozone data through 1991. J. Geophys. Res., 99, $5449-5464$.

29-SHI Xiaohui,XU Xiangde,XIE Li'an , 2007: Reliability Analyses of Anomalies of NCEP/NCAR Reanalyzed Wind Speed and Surface Air Temperature in Climate Change Research in China, Journal of Meteorological Research $₫ 2007$, Vol. 21 Issue (3): 320-333

30-Sneyers, R. (1990): On the Statistical Analysis of Series of Observations. Technical Note 143, WMO-No. 415, Geneva, 192 p.

31-Stolarski R. S. and S. M. Frith, 2006. Search for evidence of trend slow-down in the long-term TOMS/ SBUV total ozone data record: the importance of instrument drift uncertainty. Atmos. Chem. Phys. 6, 4057-4065.

32-Stolarski, R.S., Bloomfield, P., McPeters, R.D. and Herman, J.R. 1991: 'Total ozone trends deduced from Nimbus 7 TOMS data', Geophys. Res. Lett. 18, 1015.

33-Stolarski, R.S., Bojkov, R., Bishop, L., Zerefos, C., Stachelm, J. and Zaaurodny, J. 1992: Measured trends in stratospheric ozone, Science, 256, 342-349

34- Stolarski, R.S., Krueger, A.J., Schoeberl, M.R., McPeters, R.D., Newman, P.A. and Alpert, J.C., 1986: Nimbus 7 satellite measurements of the springtime Antarctic ozone decrease. Nature, 322, 808-811.

35-Trenberth, K.E., 1990: Recent observed interdecadal climate changes in the northern Hemisphere. Bull. Am. Meteorol. Soc., 71, 988-993.

36-UNEP, 1998. Environmental Effects of Ozone Depletion. United Nations Environment Programme.

37-UNEP, 2003. Environmental Effects of Ozone. Depletion: 2002 Assessment. Photochemistry and Photobiology, 2:1-72. United Nations Environment Programme.

38-W. Chehade, M. Weber, and J. P. Burrows ,2014 Total ozone trends and variability during 1979-2012 from merged data sets of various satellites Atmos. Chem. Phys., 14, 7059-7074, 2014.

39-WMO, 1994: Scientific assesment of ozone depletion, World Meteorological Organisation Report No. 37, Geneva. 
40-WMO, 2003. Scientific assessment of ozone depletion: 2002. Global ozone research and monitoring project. Report No. 47. World Meteorological Organization, Geneva, 498 pp.

41- World Meteorological Organization (WMO). 2011. 'Scientific assessment of ozone depletion: 2010', Global Ozone Research and Monitoring Project Report No. 52. WMO: Geneva, Switzerland

42-Ziemke J. R., S. Chandra and P. K. Bhartia, 2005. A 25-year data record of atmospheric ozone in the Pacific from Total Ozone Mapping Stratospheric (TOMS) cloud slicing: Implications for ozone trends in the stratosphere and troposphere. J. Geophys. Res. 110, D15105, doi:10.1029/2004JD005687.

Table 1: The name, location and available period of data of the 8 stations.

\begin{tabular}{|c|c|c|c|c|c|c|c|}
\hline Station & $\begin{array}{c}\text { WMO } \\
\text { No. }\end{array}$ & $\begin{array}{c}\text { Ozone } \\
\text { ID. }\end{array}$ & $\begin{array}{c}\text { Latitude } \\
\left({ }^{\circ}\right.\end{array}$ & $\begin{array}{c}\text { Longitude } \\
\left({ }^{\circ}\right)\end{array}$ & $\begin{array}{c}\text { Height } \\
(\mathbf{m})\end{array}$ & $\begin{array}{c}\text { Data source and } \\
\text { intsr }\end{array}$ & $\begin{array}{c}\text { Available } \\
\text { Data }\end{array}$ \\
\hline Matrouh & 62306 & 376 & $31.33^{\circ} \mathrm{N}$ & $27.22^{\circ} \mathrm{E}$ & 35 & $\begin{array}{c}\text { Brewer \# 143\& } \\
\text { Era Intrem }\end{array}$ & $1998-2014$ \\
\hline Alex & 62315 & & $31.18^{\circ} \mathrm{N}$ & $29.95^{\circ} \mathrm{E}$ & 17 & Era Intrem & $1979-2014$ \\
\hline Ismailia & 62440 & & 30.53 & 32.1 & 12 & Era Intrem & $1979-2014$ \\
\hline Cairo & 62371 & 152 & $3^{\circ} .08^{\circ} \mathrm{N}$ & $31.28^{\circ} \mathrm{E}$ & 37 & $\begin{array}{c}\text { Dobson \# 096\& } \\
\text { Era Intrem }\end{array}$ & $1968-2014$ \\
\hline Dahab & 62467 & & 28.5 & 34.5 & 18 & Era Intrem & $1979-2014$ \\
\hline Hurghada & 62464 & 409 & $27.28^{\circ} \mathrm{N}$ & $33.75^{\circ} \mathrm{E}$ & 7 & $\begin{array}{c}\text { Dobson \# 059\& } \\
\text { Era Intrem }\end{array}$ & $2001-2014$ \\
\hline Aswan & 62414 & 245 & $23.97^{\circ} \mathrm{N}$ & $32.78^{\circ} \mathrm{E}$ & 193 & $\begin{array}{c}\text { Dobson \# 069\& } \\
\text { Era Intrem }\end{array}$ & $1984-2014$ \\
\hline Ewinat & 62425 & & $22.52^{\circ} \mathrm{N}$ & $28.75^{\circ} \mathrm{E}$ & 274 & Era Intrem & $1979-2014$ \\
\hline
\end{tabular}

Table 2: Bartlet test result for the reanalysis TCO data of 8 stations $(n=12$ is the number of terms in each subperiod $k$, and $k=3$ is the number of the subperiod), also for the TCO data of 4 land based stations of Egypt.

\begin{tabular}{|c|c|c|c|c|c|c|c|c|c|c|c|c|c|c|}
\hline \multirow{3}{*}{ Station } & \multicolumn{6}{|c|}{ Reanalysis data } & \multicolumn{8}{|c|}{ Measured data } \\
\hline & \multirow{2}{*}{$\begin{array}{c}95 \% \\
\text { S. P }\end{array}$} & \multicolumn{5}{|c|}{$S_{\max }^{2} / S_{\min }^{2}$} & \multirow[t]{2}{*}{$\mathbf{n}$} & \multirow[t]{2}{*}{$\mathbf{k}$} & \multirow{2}{*}{$\begin{array}{c}95 \% \\
\text { S. P }\end{array}$} & \multicolumn{5}{|c|}{$S_{\max }^{2} / S_{\min }^{2}$} \\
\hline & & Annual & Win & Spr & Sum & Aut & & & & Annual & Win & Spr & Sum & Aut \\
\hline Matrouh & 4.5 & 1.36 & 1.27 & 2.35 & 0.93 & 1.98 & 8 & 2 & 4.99 & 0.27 & 0.47 & 0.26 & 1.20 & 1.51 \\
\hline Alex & 4.5 & 1.36 & 1.52 & 2.38 & 0.98 & 1.45 & & & & & & & & \\
\hline Ismail & 4.5 & 1.24 & 1.89 & 2.59 & 1.04 & 1.63 & & & & & & & & \\
\hline Cairo & 4.5 & 1.26 & 1.87 & 2.59 & 1.02 & 1.55 & 15 & 3 & 3.95 & 0.12 & 0.24 & 0.96 & 0.80 & 0.12 \\
\hline Dahab & 4.5 & 1.01 & 1.78 & 1.84 & 0.72 & 1.15 & & & & & & & & \\
\hline Hurgada & 4.5 & 1.15 & 1.54 & 1.78 & 1.16 & 1.45 & 7 & 2 & 5.82 & 0.59 & 0.29 & 0.62 & 5.02 & 0.31 \\
\hline Aswan & 4.5 & 1.22 & 1.01 & 1.64 & 1.34 & 1.17 & 15 & 2 & 3.14 & 0.62 & 0.98 & 0.80 & 0.76 & 1.90 \\
\hline Ewinat & 4.5 & 1.98 & 0.88 & 2.17 & 1.73 & 1.30 & & & & & & & & \\
\hline
\end{tabular}


Table 3: Annual and seasonal values of the coefficient of variation of TCO for the reanalysis and land based stations.

\begin{tabular}{|c|c|c|c|c|c|c|c|c|c|c|}
\hline \multirow{2}{*}{ Station } & \multicolumn{5}{|c|}{ Reanalysis data } & \multicolumn{5}{|c|}{ Measured data } \\
\hline & Annual & Win & Spr & Sum & Aut & Annual & Win & Spr & Sum & Aut \\
\hline Matrouh & 2.06 & 3.98 & 3.58 & 1.80 & 1.98 & 1.46 & 3.21 & 3.04 & 1.24 & 1.69 \\
\hline Alex & 2.05 & 4.04 & 3.56 & 1.76 & 1.96 & & & & & \\
\hline Ismail & 1.99 & 4.20 & 3.46 & 1.68 & 1.93 & & & & & \\
\hline Cairo & 1.99 & 4.16 & 3.49 & 1.69 & 1.91 & 2.1 & 4.41 & 3.26 & 2.02 & 2.09 \\
\hline Dahab & 1.91 & 4.15 & 3.19 & 1.65 & 1.90 & & & & & \\
\hline Hurgada & 2.14 & 5.89 & 3.17 & 1.71 & 1.92 & 1.71 & 2.23 & 1.95 & 1.95 & 1.06 \\
\hline Aswan & 1.86 & 3.62 & 2.93 & 1.76 & 1.94 & 1.70 & 3.35 & 2.67 & 2.11 & 2.59 \\
\hline Ewinat & 1.85 & 3.31 & 2.88 & 1.85 & 1.91 & & & & & \\
\hline
\end{tabular}

Table 4: Annual and seasonal trend by least square method for reanalysis and land based stations TCO data.

\begin{tabular}{|c|c|c|c|c|c|c|c|c|c|c|}
\hline \multirow{2}{*}{ Station } & \multicolumn{5}{|c|}{ Reanalysis data } & \multicolumn{5}{|c|}{ Measured data } \\
\hline & annual & win & spr & sum & Aut & annual & win & spr & Sum & Aut \\
\hline Matrouh & 0.01 & -0.26 & -0.12 & -0.03 & 0.14 & 0.53 & 0.39 & 0.57 & 0.53 & 0.46 \\
\hline Alex & -0.09 & -0.25 & -0.06 & -0.05 & 0.01 & & & & & \\
\hline Ismail & -0.05 & -0.20 & -0.07 & -0.01 & 0.06 & & & & & \\
\hline Cairo & -0.05 & -0.21 & -0.08 & -0.01 & 0.05 & 0.03 & -0.15 & 0.04 & 0.19 & 0.07 \\
\hline Dahab & -0.01 & -0.17 & -0.01 & 0.03 & 0.09 & & & & & \\
\hline Hurgada & 0.13 & -0.39 & $\mathbf{0 . 0 3}$ & $\mathbf{0 . 0 7}$ & 0.11 & 0.46 & 0.06 & 0.48 & 0.37 & 0.84 \\
\hline Aswan & 0.06 & -0.03 & 0.07 & 0.16 & 0.17 & 0.18 & 0.34 & 0.24 & 0.07 & 0.06 \\
\hline Ewinat & 0.13 & 0.03 & 0.12 & 0.13 & 0.14 & & & & & \\
\hline
\end{tabular}

Table 5: Annual and seasonal trend by Mann-Kendall rank correlation test for reanalysis and land based stations TCO data.

\begin{tabular}{|c|c|c|c|c|c|c|c|c|c|c|}
\hline \multirow{2}{*}{ Station } & \multicolumn{5}{|c|}{ Reanalysis data } & \multicolumn{5}{|c|}{ Measured data } \\
\hline & annual & win & spr & Sum & Aut & annual & win & spr & Sum & Aut \\
\hline Matrouh & -0.09 & -0.18 & -0.07 & -0.05 & -0.01 & 0.40 & 0.13 & 0.19 & 0.52 & 0.51 \\
\hline Alex & -0.09 & -0.19 & -0.04 & -0.08 & 0.013 & & & & & \\
\hline Ismail & -0.05 & -0.15 & -0.03 & 0.01 & 0.06 & & & & & \\
\hline Cairo & -0.06 & -0.14 & -0.03 & -0.01 & 0.04 & 0.13 & -0.02 & 0.03 & 0.31 & $\overline{0.11}$ \\
\hline Dahab & -0.01 & -0.09 & 0.03 & 0.06 & 0.15 & & & & & \\
\hline Hurgada & -0.03 & -0.12 & 0.06 & 0.14 & 0.17 & 0.67 & 0.05 & 0.16 & 0.36 & 0.54 \\
\hline Aswan & 0.12 & -0.04 & 0.10 & 0.26 & 0.18 & 0.26 & 0.26 & 0.23 & 0.14 & 0.21 \\
\hline Ewinat & 0.19 & 0.01 & 0.12 & 0.30 & 0.19 & & & & & \\
\hline
\end{tabular}


Table 6: The detected years of abrupt change (decreasing or increasing) of the annual TCO of the eight stations by Mann-Kendall rank statistic test.

\begin{tabular}{|c|c|c|c|c|}
\hline \multirow{2}{*}{ Station } & \multicolumn{2}{|c|}{ Reanalysis data } & \multicolumn{2}{|c|}{ Measured data } \\
\hline & Decreasing & Increasing & Decreasing & Increasing \\
\hline Matrouh & $\begin{array}{l}1981-1984- \\
2000-2013 \\
\end{array}$ & 2006 & None & None \\
\hline Alex & $\begin{array}{c}\text { 1981- 1984- } \\
2000 \\
\end{array}$ & 2006 & & \\
\hline Ismail & $\begin{array}{l}\text { 1981- 1984- } \\
\text { 1999- } 2012 \\
\end{array}$ & $2006-2014$ & & \\
\hline Cairo & $\begin{array}{l}\text { 1981- 1984- } \\
\text { 1999- } 2012 \\
\end{array}$ & 2006 & 1970 & 1980 \\
\hline Dahab & $\begin{array}{c}\text { 1981- 1985- } \\
\text { 1999- } 2012\end{array}$ & $2006-2014$ & & \\
\hline Hurgada & $\begin{array}{l}\text { 1981- 1984- } \\
2000-2010 \\
\end{array}$ & $2006-2014$ & None & None \\
\hline Aswan & $\begin{array}{c}\text { 1989- 1998- } \\
2010 \\
\end{array}$ & 1987-1993- 2008 & 2010 & 1998 to 2004 \\
\hline Ewinat & 1998- 2009 & 1986- $1993-1989$ & & \\
\hline
\end{tabular}

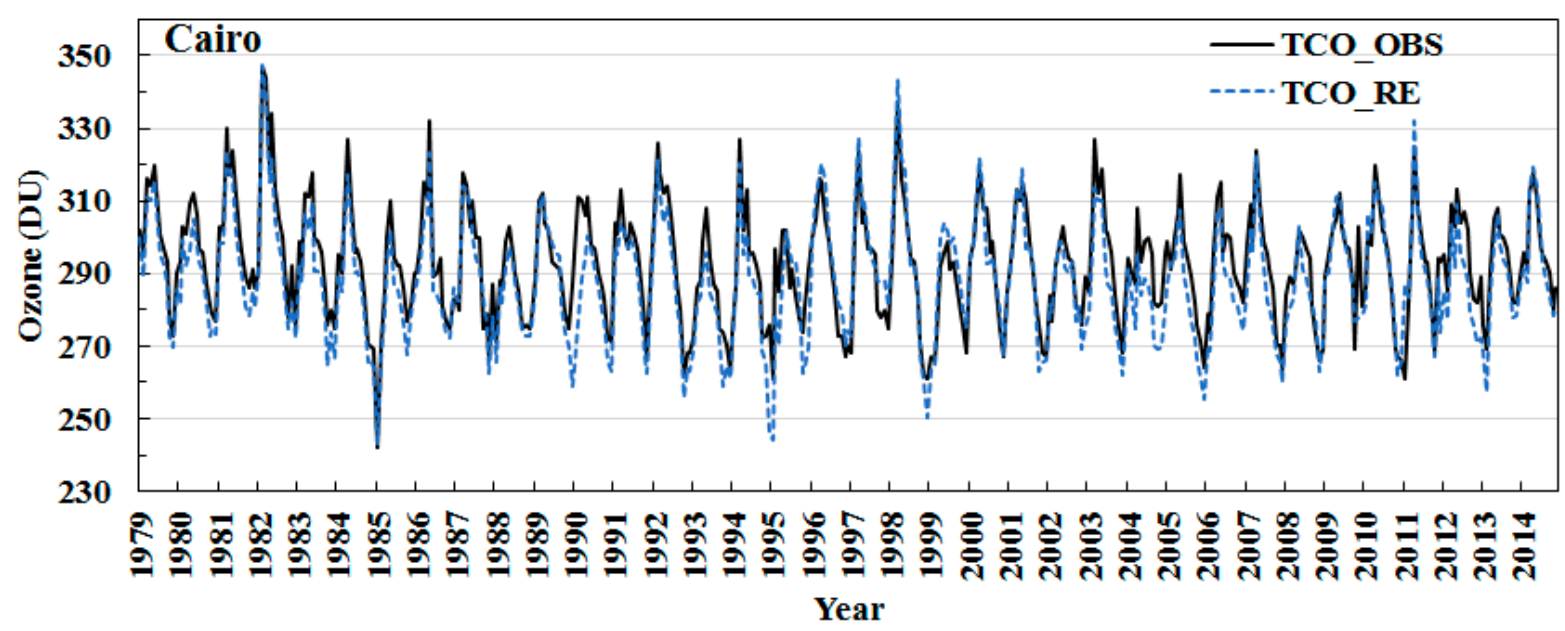

Fig. 1: The monthly values of the measured and reanalysis TCO over Cairo during the period from 1979 to 2014 


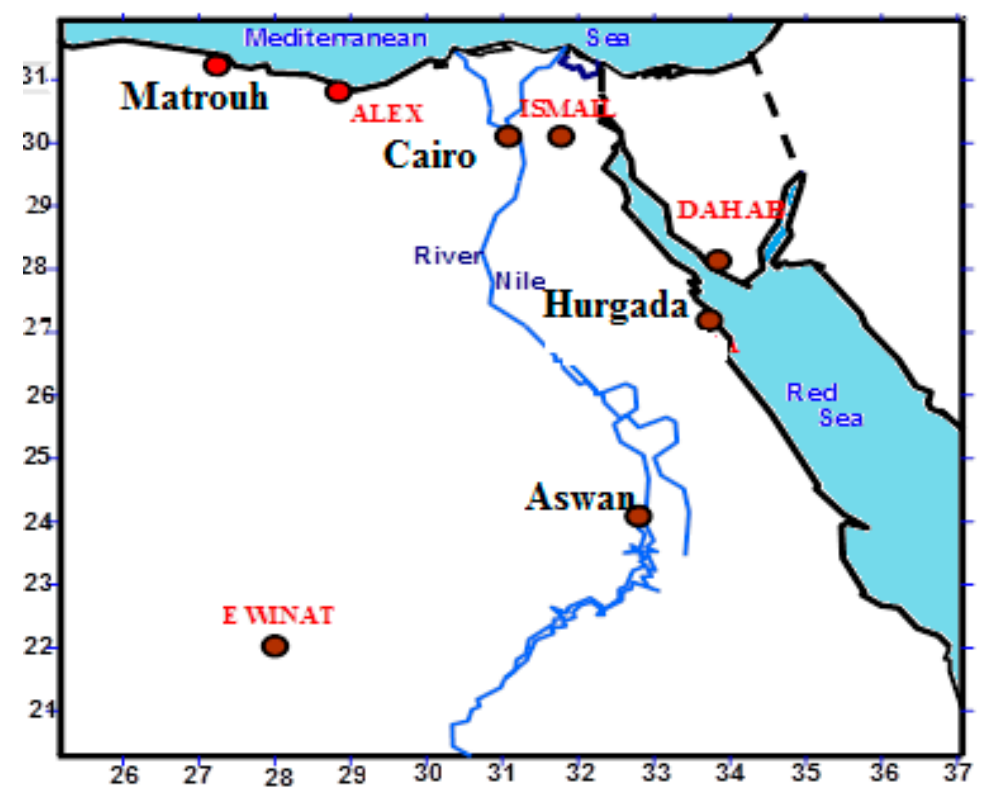

Fig. 2: The name and position of the selected stations over Egypt. 

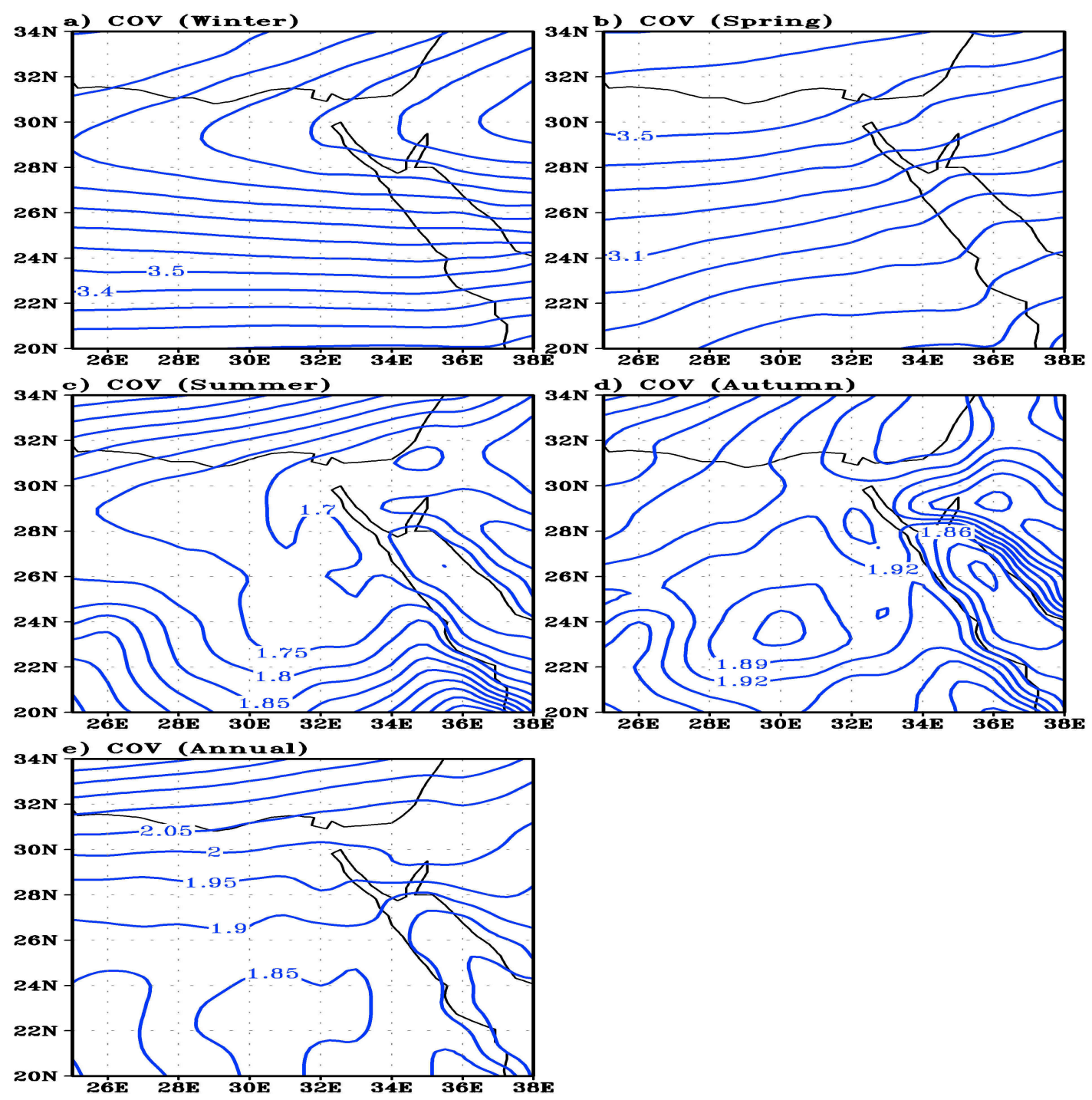

Fig. 3: Horizontal distribution of the coefficient of variation of the seasonal and annual reanalysis TCO. 

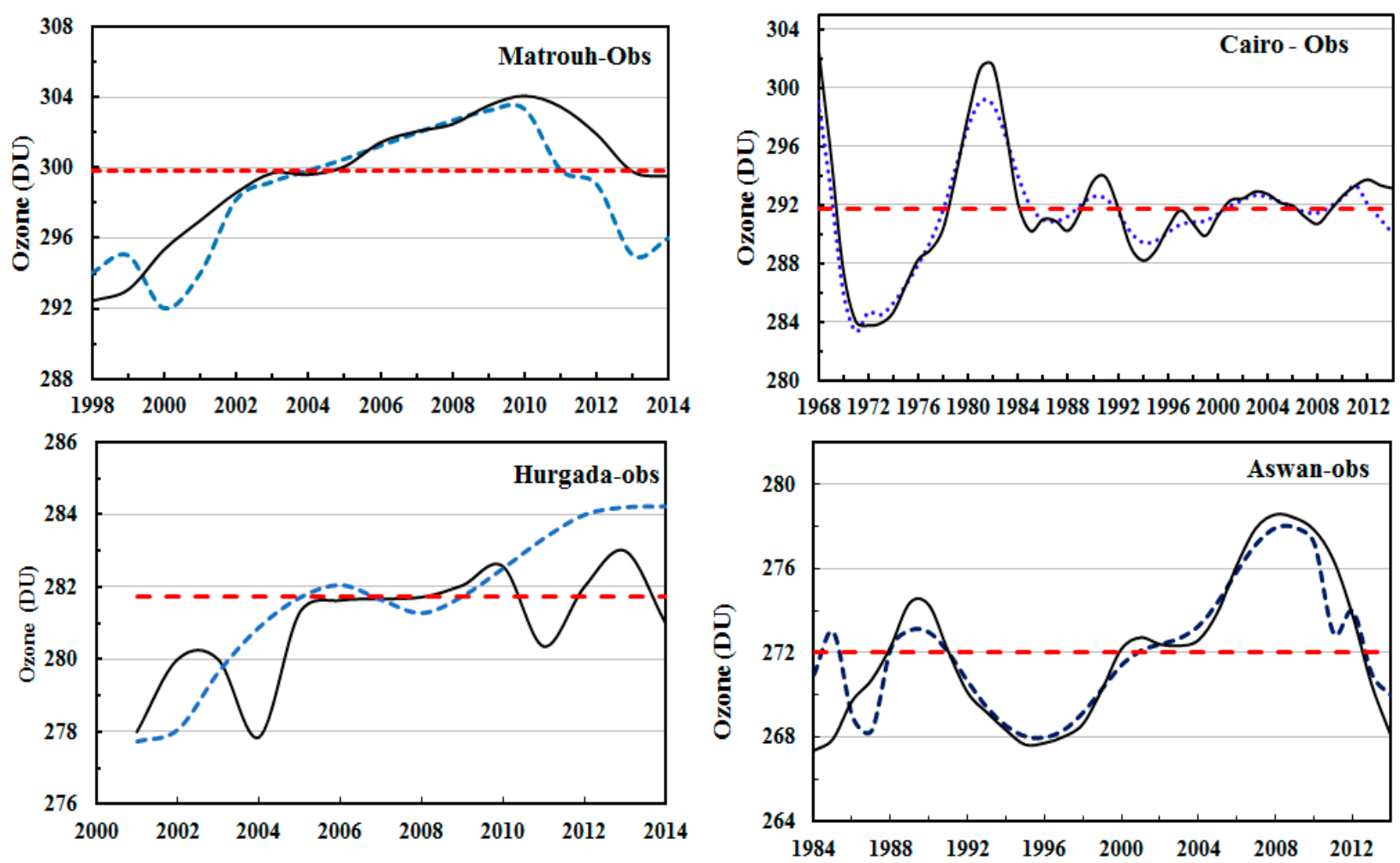

Fig 4: The fluctuations of the annual ozone of Cairo, Matrouh, Hurgada and Aswan stations, means annual ozone, Gaussian low-pass filter.

Binomial low-pass filter, 

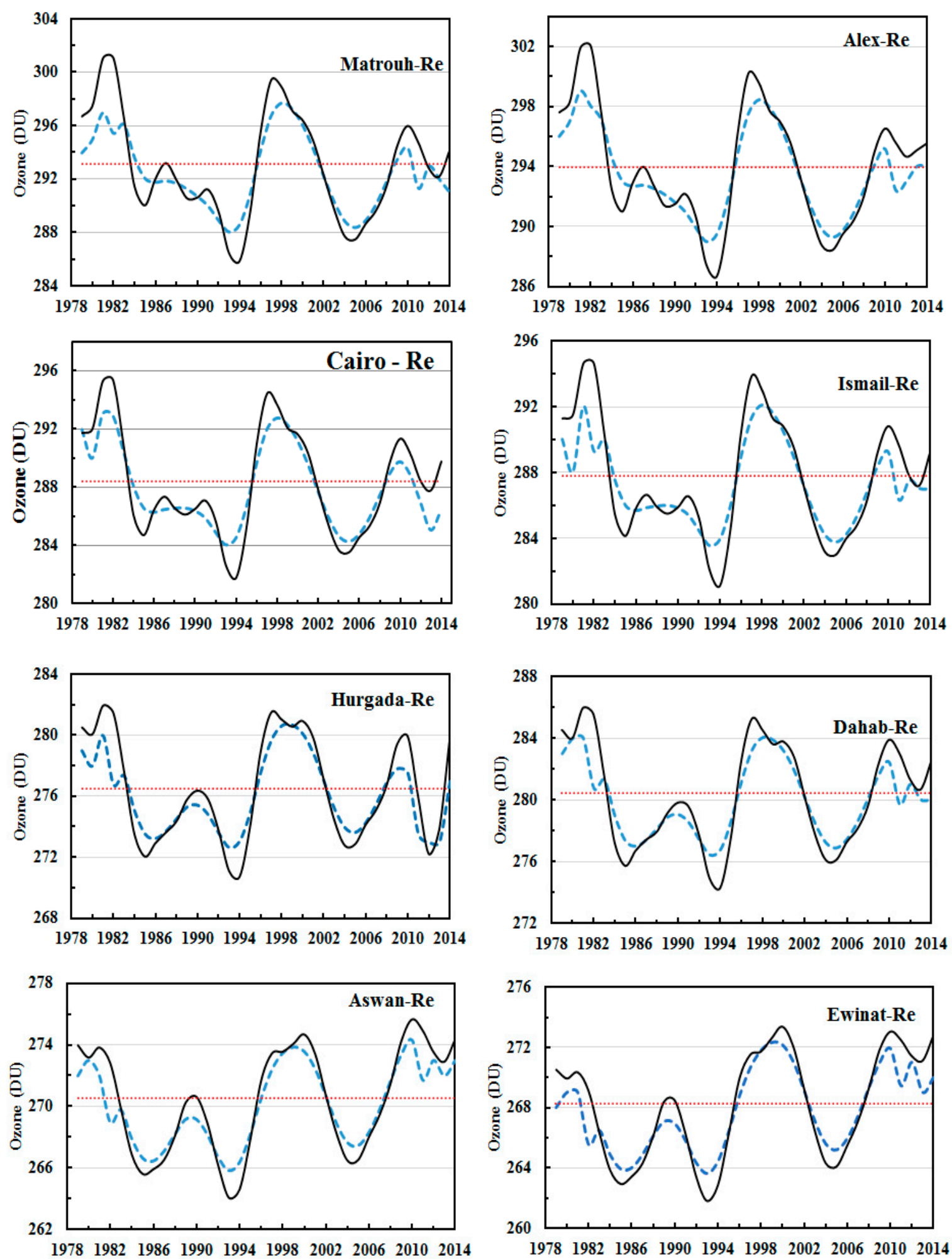

Fig 5: The fluctuations of the reanalysis annual ozone of the 8 stations, - means annual ozone, Binomial low-pass filter, Gaussian low-pass filter. 

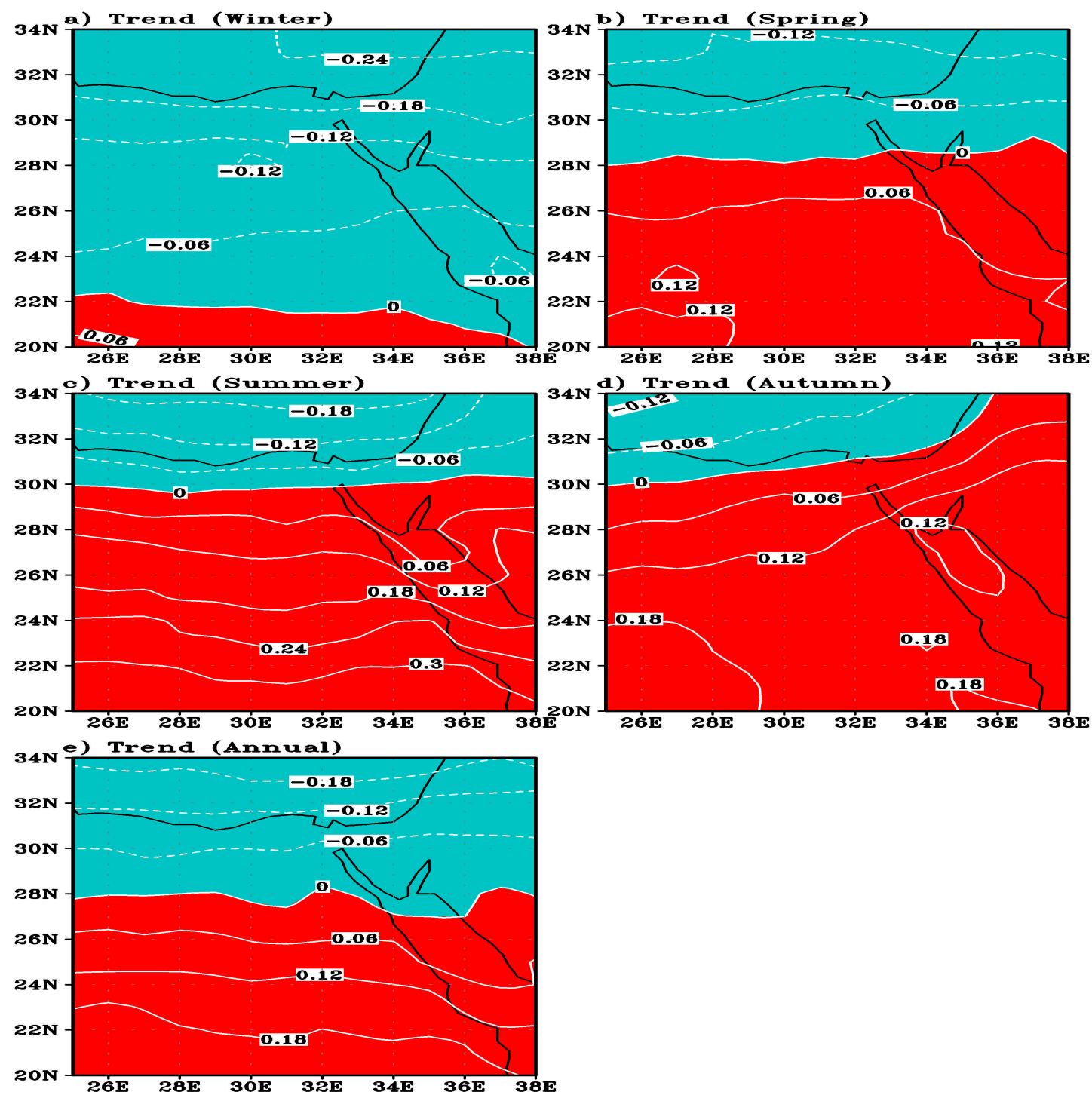

Fig. 6: The horizontal distribution of the trend values of the seasonal and annual reanalysis TCO for the period 1979-2014. 

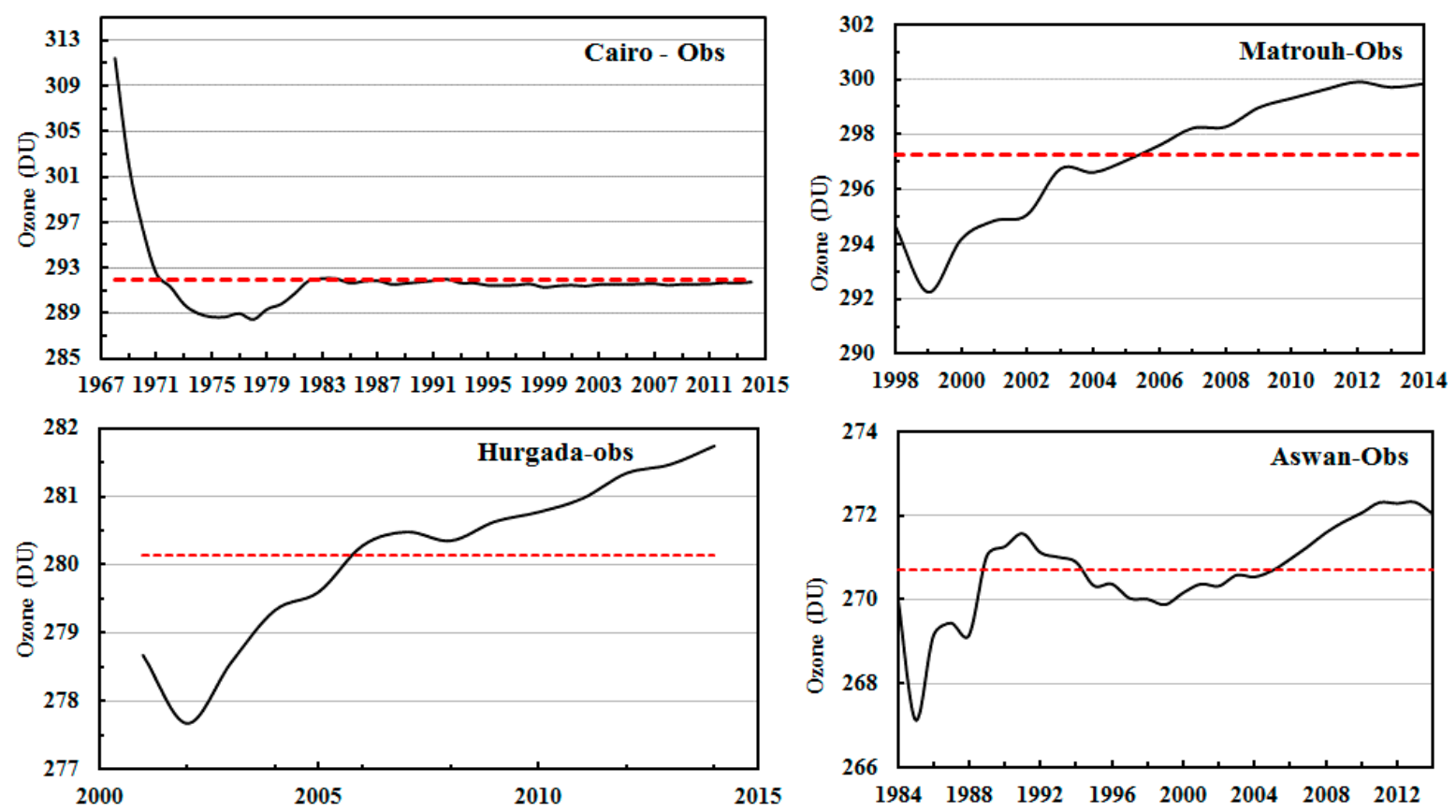

Fig. 7: The comulative annual mean (CAM) time series and the averaged CAM of measured TCO of the stations Cairo, Matrouh, Hurgada and Aswan 

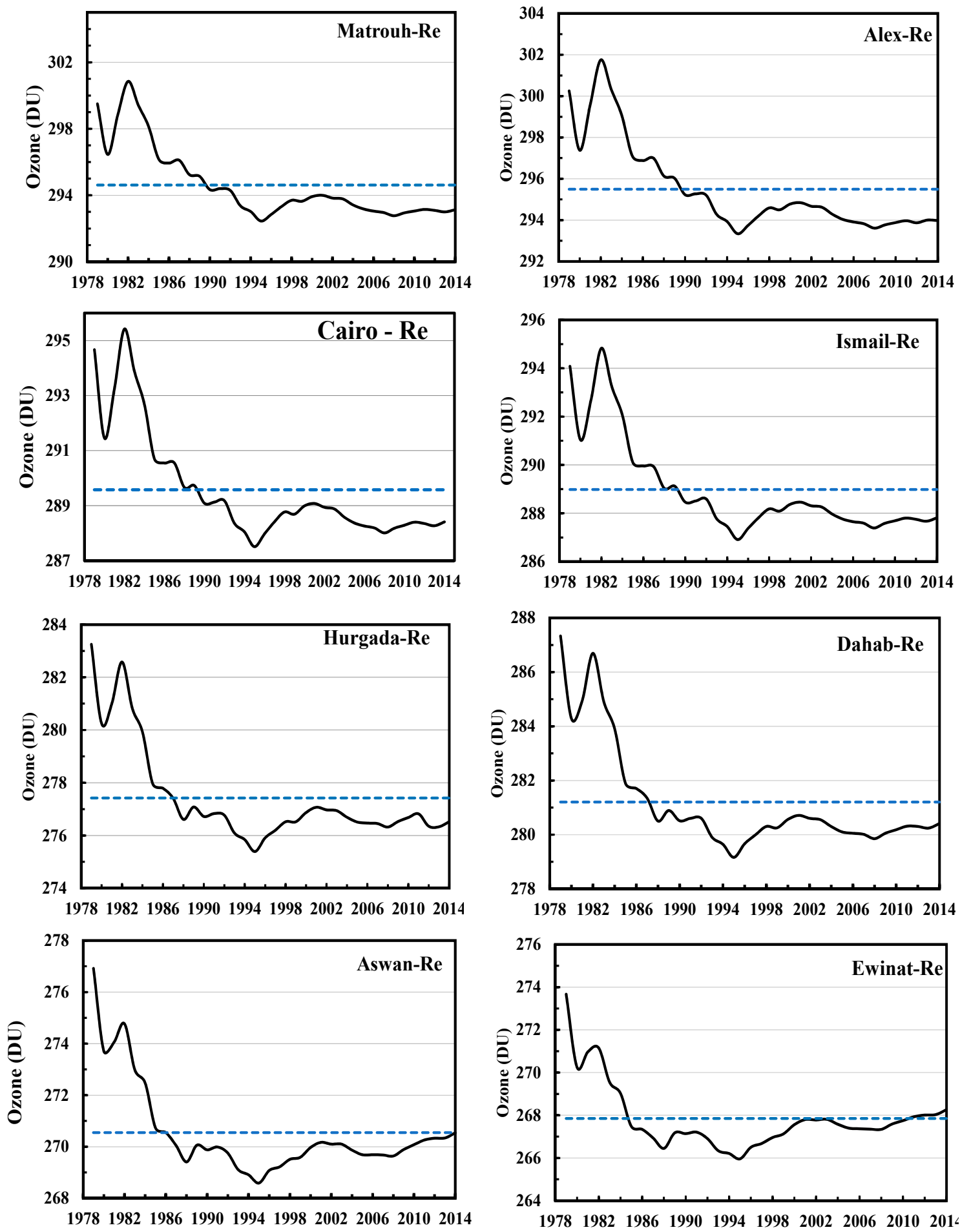

Fig. 8: The comulative annual mean (CAM) time series and the averaged CAM of the reanalysis $\mathrm{TCO}$ of the eight stations. 

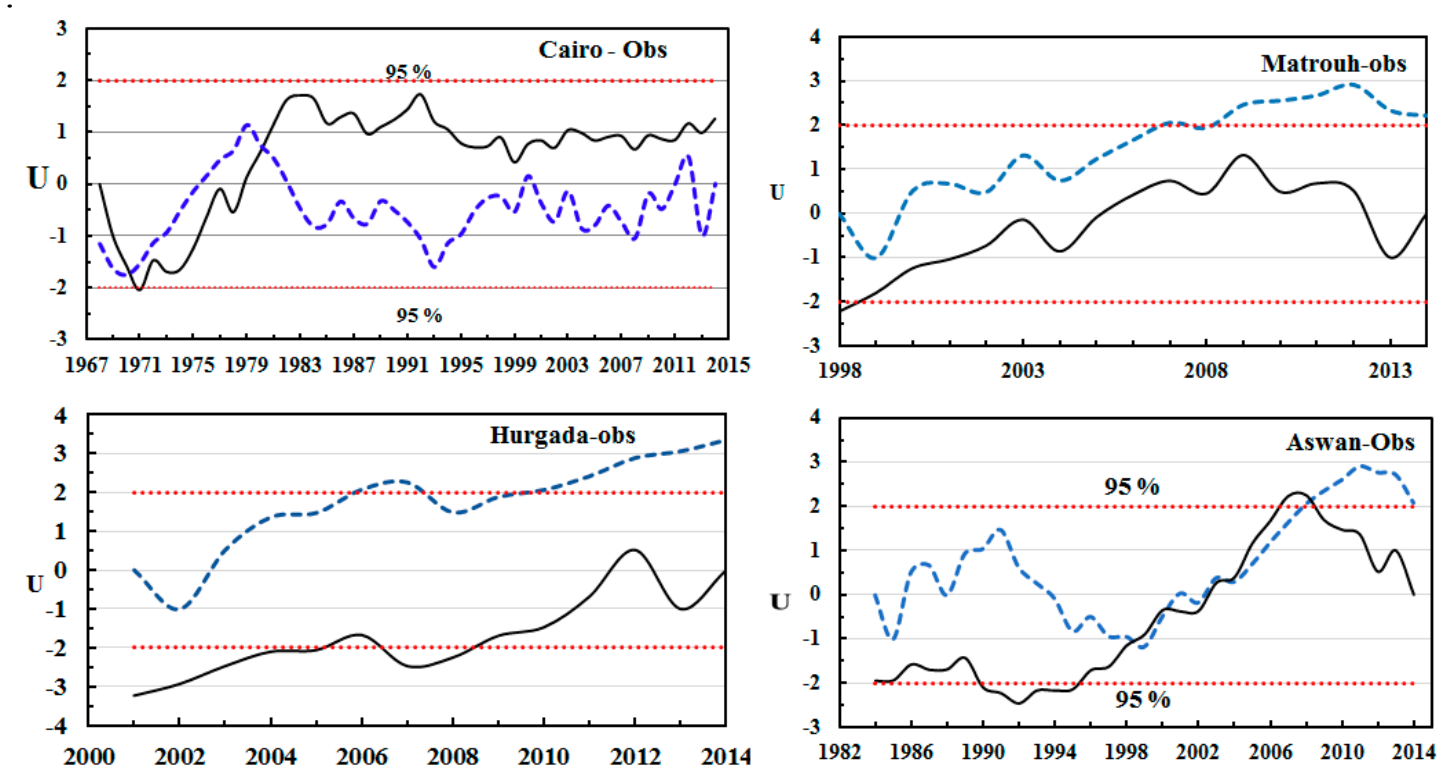

Fig. 9: Mann-Kendall test for abrupt change of the annual measured TCO of Cairo, Matrouh, Hurgada and Aswan. 

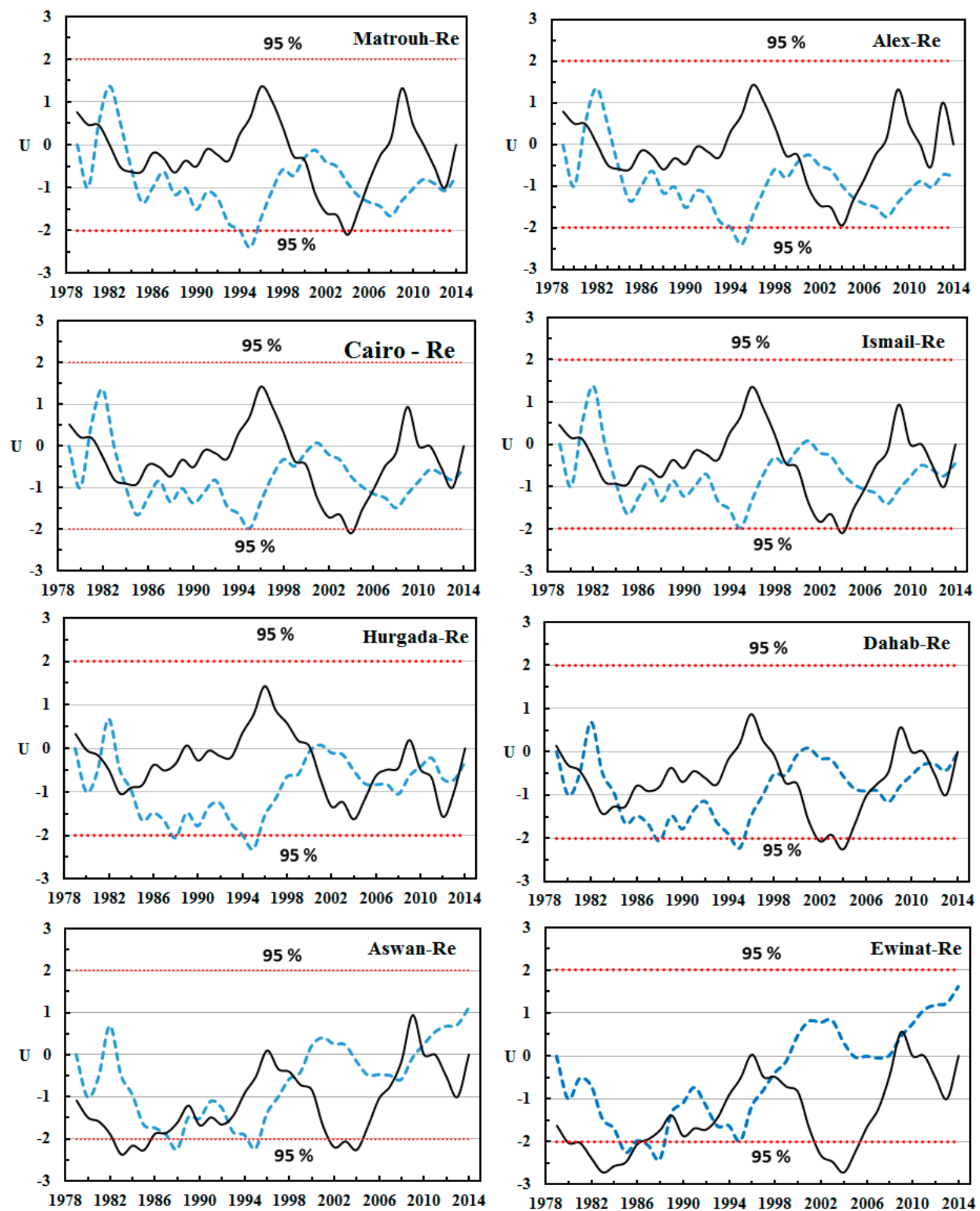

Fig. 10: Mann-Kendall test for abrupt change of the annual reanalysis TCO of the eight stations. 

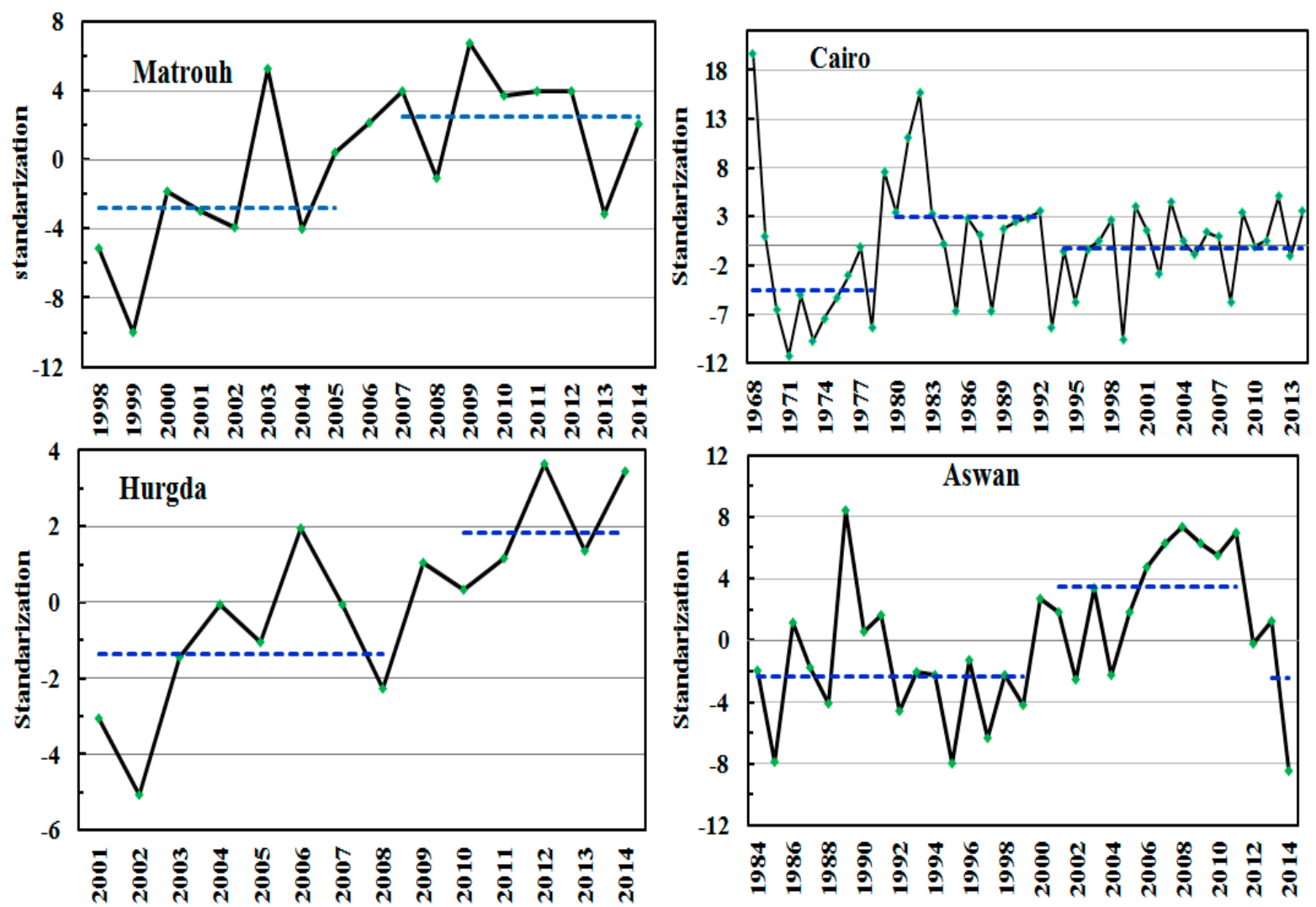

Fig. 11: Shifts in the mean for standardization of the annual measured TCO of Cairo, Matrouh, Hurgada and Aswan. (Probability $=0.1$, cutoff length $=10$, Huber parameter $=2$ )

(C) 2017 by the authors; licensee Preprints, Basel, Switzerland. This article is an open access article distributed under the terms and conditions of the Creative Commons by Attribution (CC-BY) license (http://creativecommons.org/licenses/by/4.0/). 